\title{
Determining the optimal timing of insecticide applications for control of cabbage root fly (Delia radicum L.) based on monitoring
}

\author{
Ustalenie optymalnego terminu wykonania zabiegu zwalczania \\ śmietki kapuścianej (Delia radicum L.) na podstawie monitoringu
}

\author{
Robert Wrzodak*, Katarzyna Woszczyk, Andrzej Lewandowski, Dariusz Rybczyński
}

\section{Summary}

The research to determine the optimal terms of treatments against cabbage root fly (Delia radicum L.) on early and late cultivars of white cabbage was conducted in the 2012-2013, in Research Institute of Horticulture in Skierniewice and on the farm of agricultural college in Powiercie. The efficacy of treatments applied at different times: 2, 5 and 7 days after exceeding the threshold of harmfulness were compared in the field experiments. The treatment performed five days after exceeding the threshold of harmfulness provided the best result. The developed method will be the basis of integrated brassica crop protection against cabbage root fly.

Key words: cabbage root fly; monitoring; efficacy of treatments

\section{Streszczenie}

W latach 2012-2013 w Instytucie Ogrodnictwa oraz w gospodarstwie Zespołu Szkół Rolniczych w Powierciu prowadzono badania mające na celu ustalenie optymalnych terminów wykonywania zabiegów zwalczania śmietki kapuścianej (Delia radicum L.) na wczesnych i późnych odmianach kapusty głowiastej białej. Monitorowanie nalotu prowadzono przy użyciu pułapki zapachowej. W doświadczeniach porównano skuteczność zabiegów wykonanych w różnych terminach: 2, 5 i 7 dni po przekroczeniu ustalonego progu szkodliwości. Najlepsze efekty w zwalczaniu śmietki kapuścianej uzyskano przeprowadzając zabieg w terminie 5 dni po przekroczeniu progu szkodliwości. Opracowana metoda będzie stanowić podstawę integrowanej ochrony warzyw kapustnych przed śmietką kapuścianą.

Słowa kluczowe: śmietka kapuściana; monitoring; skuteczność zwalczania

nstytut Ogrodnictwa

Konstytucji 3 Maja 1/3, 96-100 Skierniewice

*corresponding author: robert.wrzodak@inhort.pl 


\section{Wstęp / Introduction}

Kapusta głowiasta jest jednym z podstawowych gatunków warzyw powszechnie uprawianych na terenie całego kraju. Jako jedna z roślin żywicielskich jest naturalną bazą pokarmową dla wielu fitofagicznych gatunków owadów. Od roku 1919, kiedy rozpoczęto ogólnopolską, coroczną rejestrację szkodników (Ruszkowski 1933; Ruszkowski i wsp. 1935; Szwejda 1999) do chwili obecnej, na krajowych uprawach warzyw kapustnych stwierdzono występowanie blisko 86 gatunków szkodliwych owadów (Szwejda 2004, 2010).

Zdecydowanym dominantem w tej grupie szkodników jest śmietka kapuściana (Delia radium L.). Stadium szkodliwym są larwy, które przy zaniechaniu ochrony mogą powodować uszkodzenia plonu sięgające 80\% (Szwejda 1975). Od lat prowadzone są doświadczenia dotyczące ochrony kapusty przed tym szkodnikiem. Jedną z głównych przyczyn nieskutecznej ochrony przed śmietką są nieterminowo przeprowadzane zabiegi ochronne. W ostatnich latach w Instytucie Ogrodnictwa w Skierniewicach podjęto badania nad ustaleniem optymalnych terminów wykonywania zabiegów zwalczania śmietki kapuścianej na plantacjach warzyw kapustnych.

Celem badań było określenie skuteczności zabiegów ochronnych, wykonywanych w oparciu o sygnalizację pojawu szkodnika, prowadzonych przy użyciu pułapek zapachowych oraz ustalenie optymalnego terminu dla ich przeprowadzania. Skuteczna ochrona upraw kapusty przed śmietką kapuścianą pozwoli na ograniczenie liczby zabiegów ochronnych. Uzyskane wyniki będą stanowiły podstawę do prowadzenia integrowanej ochrony warzyw kapustnych przed śmietką kapuścianą.

\section{Materiały i metody / Materials and methods}

Doświadczenia wykonano w latach 2012-2013 na polach Instytutu Ogrodnictwa w Skierniewicach oraz w gospodarstwie Zespołu Szkół Centrum Kształcenia Rolniczego w Powierciu, w uprawach wczesnej i późnej kapusty głowiastej. Powierzchnia każdej uprawy wynosiła $200 \mathrm{~m}^{2}$.

Monitoring nalotu prowadzono przy użyciu pułapek zapachowych, zawierających wabik z izotiocyjanianem allilu (Traynier 1965; Eckenrode i Arn 1972; Finch i Skinner 1974, 1982). W każdej uprawie ustawiono po dwie pułapki, które były mocowane na palikach pozwalających na zmianę wysokości ich mocowania tak, aby znajdowały się nad wierzchołkami rosnących roślin (Rogowska i Szwejda 2002).

Odczyty liczby odłowionych samic śmietki prowadzono 2-, 3-krotnie w ciągu tygodnia, przez cały okres wegetacji. Na tej podstawie, po przekroczeniu progu szkodliwości, tzn. odłowieniu się do pułapki 2 samic dziennie przez 2 kolejne dni obserwacji (średnia z dwóch pułapek) określano terminy przeprowadzenia zabiegów (Szwejda i Wrzodak 2006). Zabiegi opryskiwania wykonywano 2, 5 i 7 dni po przekroczeniu ustalonego progu szkodliwości. Do zwalczania śmietki kapuścianej zastosowano insektycyd zawierający jako substancję czynną lambda-cyhalotrynę, w dawce 0,12 1/ha.
Skuteczność zabiegów ochronnych przeciw śmietce kapuścianej oceniano na podstawie analiz roślin przeprowadzonych w okresie zbiorów, gdzie na każdym poletku liczono rośliny uszkodzone przez larwy śmietki. Uzyskane wyniki opracowano statystycznie i oceniono testem Newmana-Keulsa, przy poziomie istotności $\mathrm{p}=0,05$.

\section{Wyniki i dyskusja / Results and discussion}

Monitoring prowadzony przy pomocy pułapek zapachowych pozwolił, podobnie jak we wcześniejszych doświadczeniach, na określenie początku lotu pierwszego i drugiego pokolenia śmietki kapuścianej (Rogowska i Szwejda 2002).

W 2012 roku pierwsze pokolenie śmietki rozpoczęło lot w drugiej dekadzie maja, a drugie pokolenie - w trzeciej dekadzie lipca. W czasie prowadzenia monitoringu w Skierniewicach odłowiono łącznie 188, a w Powierciu 117 samic śmietki kapuścianej.

W roku 2013 loty pierwszego i drugiego pokolenia rozpoczęły się dwa-trzy tygodnie wcześniej niż w roku poprzednim. Potwierdza to wcześniejsze obserwacje Szwejdy (1975) oraz Szwejdy i Wrzodaka (2005) o występowaniu różnic $\mathrm{w}$ długości okresu rozwoju u tego gatunku, które mogą wynosić od 2 do 5 tygodni i są w dużym stopniu zależne od przebiegu pogody w tym okresie. W drugim roku prowadzenia doświadczeń, podczas monitorowania lotu I i II pokolenia śmietki kapuścianej, odłowiono prawie 2,5-krotnie mniej samic śmietki niż w 2012 roku, odpowiednio 75 sztuk w Skierniewicach i 45 sztuk w Powierciu (tab. 1, 2).

Prowadzenie monitoringu przy użyciu pułapek zapachowych pozwoliło na wyznaczenie momentu przekroczenia progu ekonomicznej szkodliwości oraz na wyznaczenie terminów przeprowadzenia ochronnych zabiegów opryskiwania, co potwierdza wyniki uzyskane we wcześniejszych badaniach (Szwejda i Wrzodak 2005).

W obu latach badań największą liczbę roślin zdrowych, bez uszkodzeń spowodowanych przez żerujące larwy śmietki, stwierdzono w kombinacji, w której zabiegi ochronne wykonywano 5 dni po przekroczeniu progu szkodliwości. Skuteczność zabiegów wyniosła około 91\%. Niższą skuteczność zabiegów zaobserwowano w kombinacjach, w których zabiegi były wykonywane w 2. i 7. dniu po przekroczeniu progu. Stwierdzono odpowiednio od 74 do 83 i od 82 do $90 \%$ skuteczności, przy czym wyniki uzyskane $\mathrm{w}$ kombinacji $\mathrm{z}$ zabiegiem przeprowadzonym 2 dni po przekroczeniu progu szkodliwości charakteryzowały się najwyższym odchyleniem standardowym (rys. 1). Sugerować to może większy wpływ czynników zewnętrznych na wyniki uzyskane w tej kombinacji. Autorzy niniejszej pracy przypuszczają, że jednym z nich mogą być opady występujące w okresie lotu muchówek, których wielkość była różna w czasie prowadzenia doświadczeń i mogła wpłynąć na dynamikę nalotu śmietki na rośliny. O możliwości wpływu wysokości temperatury i wielkości opadów na dynamikę lotu śmietki kapuścianej informuje również Szwejda (1975). W badaniach własnych wielkość opadów w trakcie lotu pierwszego pokolenia wyniosła od 16 do $26 \mathrm{~mm}$ w roku 2012, podczas gdy w roku 2013 od 80 do $110 \mathrm{~mm}$. 
Tabela 1. Wyniki monitorowania nalotu śmietki kapuścianej i terminy wykonania zabiegów zwalczania, Skierniewice, lata 2012-2013

Table 1. Number of captured cabbage root fly females and terms of treatments, Skierniewice 2012-2013

\begin{tabular}{l|c|c||c|c}
\hline & \multicolumn{2}{|c||}{ Rok - Year 2012 } & \multicolumn{2}{c}{ Rok - Year 2013 } \\
\hline $\begin{array}{l}\text { Pokolenia śmietki kapuścianej } \\
\text { Generation of cabbage root fly }\end{array}$ & $\begin{array}{c}\text { I pokolenie } \\
\text { I generation }\end{array}$ & $\begin{array}{c}\text { II pokolenie } \\
\text { II generation }\end{array}$ & $\begin{array}{c}\text { I pokolenie } \\
\text { I generation }\end{array}$ & $\begin{array}{c}\text { II pokolenie } \\
\text { II generation }\end{array}$ \\
\hline $\begin{array}{l}\text { Terminy odłowu pierwszych samic } \\
\text { Dates of catching the first females }\end{array}$ & $15 \mathrm{~V}$ & 21 VII & $28 \mathrm{IV}$ & 2 VII \\
\hline $\begin{array}{l}\text { Suma odłowionych samic } \\
\text { Total number of caught females }\end{array}$ & 46 & 142 & 16 & 59 \\
\hline
\end{tabular}

Terminy zabiegów - Po przekroczeniu progu szkodliwości:

Dates of treatments - After exceeding the threshold of harmfulness:

\begin{tabular}{l|c|c||c|c}
\hline 2 dni po -2 days after & $23,30 \mathrm{~V}$ & $24,31 \mathrm{VII}$ & $6,13 \mathrm{~V}$ & $15,22 \mathrm{VII}$ \\
\hline 5 dni po -5 days after & $26 \mathrm{~V}, 2 \mathrm{VI}$ & 27 VII, 3 VIII & $9,16 \mathrm{~V}$ & $18,25 \mathrm{VII}$ \\
\hline 7 dni po -7 days after & $28 \mathrm{~V}, 4 \mathrm{VI}$ & 29 VII, 5 VIII & $11,17 \mathrm{~V}$ & $20,27 \mathrm{VII}$ \\
\hline
\end{tabular}

Tabela 2. Wyniki monitorowania nalotu śmietki kapuścianej i terminy wykonania zabiegów zwalczania, Powiercie, lata 2012-2013

Table 2. Number of captured cabbage root fly females and terms of treatments, Powiercie 2012-2013

\begin{tabular}{l|c|c||c|c}
\hline & \multicolumn{2}{|c||}{ Rok - Year 2012 } & \multicolumn{2}{c}{ Rok - Year 2013 } \\
\hline $\begin{array}{l}\text { Pokolenia śmietki kapuścianej } \\
\text { Generation of cabbage root fly }\end{array}$ & $\begin{array}{c}\text { I pokolenie } \\
\text { I generation }\end{array}$ & $\begin{array}{c}\text { II pokolenie } \\
\text { II generation }\end{array}$ & $\begin{array}{c}\text { I pokolenie } \\
\text { I generation }\end{array}$ & $\begin{array}{c}\text { II pokolenie } \\
\text { II generation }\end{array}$ \\
\hline $\begin{array}{l}\text { Terminy odłowu pierwszych samic } \\
\text { Dates of catching the first females }\end{array}$ & $10 \mathrm{~V}$ & $18 \mathrm{VII}$ & $26 \mathrm{IV}$ & $6 \mathrm{VII}$ \\
\hline $\begin{array}{l}\text { Suma odłowionych samic } \\
\text { Total number of caught females }\end{array}$ & 28 & 89 & 11 & 34 \\
\hline
\end{tabular}

Terminy zabiegów - Po przekroczeniu progu szkodliwości:

Dates of treatments - After exceeding the threshold of harmfulness:

\begin{tabular}{l|l|l||c|c}
\hline 2 dni po -2 days after & $17,24 \mathrm{~V}$ & $23,30 \mathrm{VII}$ & $9,16 \mathrm{~V}$ & $19,26 \mathrm{VII}$ \\
\hline 5 dni po -5 days after & $20,27 \mathrm{~V}$ & $26 \mathrm{VII}, 2 \mathrm{VIII}$ & $12,19 \mathrm{~V}$ & $22,29 \mathrm{VII}$ \\
\hline 7 dni po -7 days after & $22,29 \mathrm{~V}$ & $28 \mathrm{VII}, 4 \mathrm{VIII}$ & $14,21 \mathrm{~V}$ & $24,31 \mathrm{VII}$ \\
\hline
\end{tabular}

Pomimo wskazanych powyżej różnic w poziomach skuteczności osiągniętych $\mathrm{w}$ poszczególnych kombinacjach, okazały się one nieistotne statystycznie (tab. 3, 4, 5, 6).

Obecnie monitoring zasiedlania plantacji warzyw przez niektóre gatunki szkodników jest prowadzony $\mathrm{z}$ wykorzystaniem różnych technik (Talhouk 2002). Do prowa- dzenia sygnalizacji wykorzystywane są między innymi pułapki: zawierające feromony (agregacyjne, płciowe), mechaniczne (odławianie, tablice lepowe) (Bracken 1988; Bligaard i wsp. 1999), świetlne (Franz i Krieg 1975; Ravn i Esbjerg 1994; Paruch 2001), a także programy komputerowe wykorzystujące symulacyjne modele mate-

Tabela 3. Porównanie skuteczności zabiegów ochronnych przeciw śmietce kapuścianej, wykonywanych po przekroczeniu progu szkodliwości wyznaczanego przy użyciu pułapek zapachowych

Table 3. Comparison of the efficacy of treatments carried out based on the threshold of harmfulness, determined by using the odor traps Skierniewice, 2012

Terminy zabiegów - Po przekroczeniu progu szkodliwości:

Dates of treatments

based on the threshold of harmfulness:
Średnia liczba uszkodzonych roślin/poletko (40 roślin) Mean number of injured plants/plot (40 plants)

\begin{tabular}{|c|c|c|}
\hline \multirow{2}{*}{$\begin{array}{l}\text { Terminy zabiegów - Po przekroczeniu } \\
\text { progu szkodliwości: } \\
\text { Dates of treatments } \\
\text { based on the threshold of harmfulness: }\end{array}$} & \multicolumn{2}{|c|}{$\begin{array}{l}\text { Średnia liczba uszkodzonych roślin/poletko (40 roślin) } \\
\text { Mean number of injured plants/plot (40 plants) }\end{array}$} \\
\hline & $\begin{array}{l}\text { I pokolenie śmietki kapuścianej } \\
\text { I generation of cabbage root fly }\end{array}$ & $\begin{array}{l}\text { II pokolenie śmietki kapuścianej } \\
\text { II generation of cabbage root fly }\end{array}$ \\
\hline 2 dni po -2 days after & $2,25 \mathrm{a}$ & $8,0 \mathrm{a}$ \\
\hline 5 dni po -5 days after & $1,5 \mathrm{a}$ & $4,0 \mathrm{a}$ \\
\hline 7 dni po -7 days after & $4,0 \mathrm{a}$ & $5,25 \mathrm{a}$ \\
\hline Kontrola-Check & $19,5 \mathrm{~b}$ & $28,0 \mathrm{~b}$ \\
\hline
\end{tabular}

Test Newmana-Keulsa, $\alpha=0,05$ - The Newman-Keuls test, $\alpha=0.05$

Średnie oznaczone tymi samymi literami nie różnią się istotnie przy $\alpha=0,05$ - The mean numbers with the same letter are not significantly different at $\alpha=0.05$ 
Tabela 4. Porównanie skuteczności zabiegów ochronnych przeciw śmietce kapuścianej, wykonywanych po przekroczeniu progu szkodliwości wyznaczanego przy użyciu pułapek zapachowych

Table 4. Comparison of the efficacy of treatments carried out based on the threshold of harmfulness, determined by using the odor traps

Skierniewice, 2013

\begin{tabular}{l|c|c}
\hline \multirow{2}{*}{$\begin{array}{c}\text { Terminy zabiegów - Po przekroczeniu } \\
\text { progu szkodliwości: } \\
\begin{array}{c}\text { Dates of treatments } \\
\text { based on the threshold of harmfulness: }\end{array}\end{array}$} & $\begin{array}{c}\text { Srednia liczba uszkodzonych roślin/poletko (40 roślin) } \\
\text { Mean number of injured plants/plot (40 plants) }\end{array}$ \\
\cline { 2 - 3 } & $\begin{array}{c}\text { I pokolenie śmietki kapuścianej } \\
\text { I generation of cabbage root fly }\end{array}$ & $\begin{array}{c}\text { II pokolenie śmietki kapuścianej } \\
\text { II generation of cabbage root fly }\end{array}$ \\
\hline 2 dni po -2 days after & $4,25 \mathrm{a}$ & $6,5 \mathrm{a}$ \\
\hline 5 dni po -5 days after & $1,75 \mathrm{a}$ & $2,5 \mathrm{a}$ \\
\hline 7 dni po -7 days after & $2,25 \mathrm{a}$ & $3,5 \mathrm{a}$ \\
\hline Kontrola - Check & $15,5 \mathrm{~b}$ & $25,25 \mathrm{~b}$ \\
\hline
\end{tabular}

Test Newmana-Keulsa, $\alpha=0,05-$ The Newman-Keuls test, $\alpha=0.05$

Średnie oznaczone tymi samymi literami nie różnią się istotnie przy $\alpha=0,05$ - The mean numbers with the same letter are not significantly different at $\alpha=0.05$

Tabela 5. Porównanie skuteczności zabiegów ochronnych przeciw śmietce kapuścianej, wykonywanych po przekroczeniu progu szkodliwości wyznaczanego przy użyciu pułapek zapachowych

Table 5. Comparison of the efficacy of treatments carried out based on the threshold of harmfulness, determined by using the odor traps

Powiercie, 2012

\begin{tabular}{l|c|c}
\hline \multirow{2}{*}{$\begin{array}{c}\text { Terminy zabiegów - Po przekroczeniu } \\
\text { progu szkodliwości: }\end{array}$} & \multicolumn{2}{|c}{$\begin{array}{c}\text { Śednia liczba uszkodzonych roślin/poletko (40 roślin) } \\
\text { Dates of treatments }\end{array}$} \\
\cline { 2 - 3 } based on the threshold of harmfulness: & $\begin{array}{c}\text { I pokolenie śmietki kapuścianej } \\
\text { I generation of cabbage root fly }\end{array}$ & $\begin{array}{c}\text { II pokolenie śmietki kapuścianej } \\
\text { II generation of cabbage root fly }\end{array}$ \\
\hline 2 dni po -2 days after & $1,75 \mathrm{a}$ & $6,5 \mathrm{a}$ \\
\hline 5 dni po -5 days after & $1,0 \mathrm{a}$ & $2,25 \mathrm{a}$ \\
\hline 7 dni po -7 days after & $3,0 \mathrm{a}$ & $3,25 \mathrm{a}$ \\
\hline Kontrola - Check & $15,75 \mathrm{~b}$ & $30,5 \mathrm{~b}$ \\
\hline
\end{tabular}

Test Newmana-Keulsa, $\alpha=0,05$ - The Newman-Keuls test, $\alpha=0.05$

Średnie oznaczone tymi samymi literami nie różnią się istotnie przy $\alpha=0,05$ - The mean numbers with the same letter are not significantly different at $\alpha=0.05$

Tabela 6. Porównanie skuteczności zabiegów ochronnych przeciw śmietce kapuścianej, wykonywanych po przekroczeniu progu szkodliwości wyznaczanego przy użyciu pułapek zapachowych

Table 6. Comparison of the efficacy of treatments carried out based on the threshold of harmfulness, determined by using the odor traps

Powiercie, 2013

\begin{tabular}{l|c|c}
\hline \multirow{2}{*}{$\begin{array}{c}\text { Terminy zabiegów - Po przekroczeniu } \\
\text { progu szkodliwości: } \\
\begin{array}{c}\text { Dates of treatments } \\
\text { based on the threshold of harmfulness: }\end{array}\end{array}$} & $\begin{array}{c}\text { Średnia liczba uszkodzonych roślin/poletko (40 roślin) } \\
\text { Mean number of injured plants/plot (40 plants) }\end{array}$ \\
\cline { 2 - 3 } & $\begin{array}{c}\text { I pokolenie śmietki kapuścianej } \\
\text { I generation of cabbage root fly }\end{array}$ & $\begin{array}{c}\text { II pokolenie śmietki kapuścianej } \\
\text { II generation of cabbage root fly }\end{array}$ \\
\hline 2 dni po -2 days after & $2,25 \mathrm{a}$ & $4,5 \mathrm{a}$ \\
\hline 5 dni po -5 days after & $0,5 \mathrm{a}$ & $1,5 \mathrm{a}$ \\
\hline 7 dni po -7 days after & $1,25 \mathrm{a}$ & $2,5 \mathrm{a}$ \\
\hline Kontrola - Check & $12,25 \mathrm{~b}$ & $18,5 \mathrm{~b}$ \\
\hline
\end{tabular}

Test Newmana-Keulsa, $\alpha=0,05$ - The Newman-Keuls test, $\alpha=0.05$

Średnie oznaczone tymi samymi literami nie różnią się istotnie przy $\alpha=0,05$ - The mean numbers with the same letter are not significantly different at $\alpha=0.05$

matyczne (Collier i wsp. 1991). Wykonuje się również próby wykorzystywania sygnalizacji satelitarnej i technik biologii molekularnej (Boczek i Dąbrowski 2005). W aktualnych systemach sygnalizacji zagrożeń upowszechnia się przede wszystkim pułapki feromonowe ze względu na ich wysoką selektywność. W większości są to pułapki służące do odłowu szkodliwych gatunków z rzędu motyli (Wiech i wsp. 2001; Rogowska 2005).

W przypadku śmietki kapuścianej, jak do tej pory, na skalę ogólnopolską nie wprowadzono jednolitego systemu monitoringu nalotu tego szkodnika na plantacje. Dodatkowo brak zarejestrowanych zapraw insektycydowych 


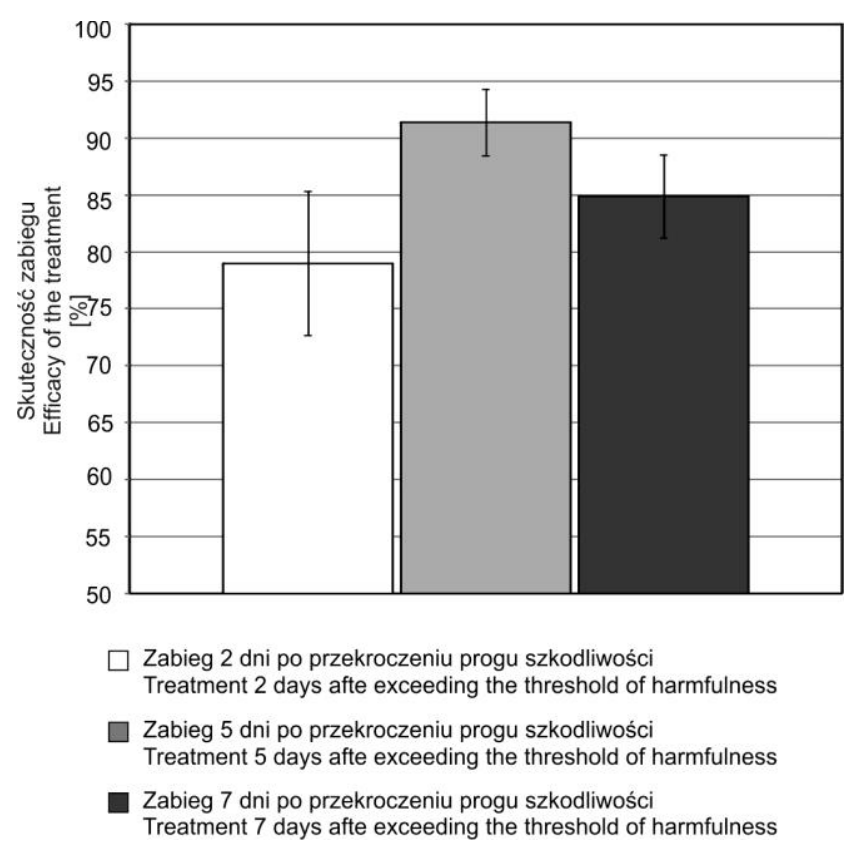

Rys. 1. Porównanie skuteczności zabiegów ochronnych przeprowadzonych 2 , 5 i 7 dni po przekroczeniu progu szkodliwości

Fig. 1. Comparison of the efficacy of treatments carried out 2, 5 and 7 days after exceeding the threshold of harmfulness Skierniewice, Powiercie for 2012-2013

w Polsce sprawia, że jedyną możliwością zwalczania śmietki kapuścianej jest prowadzenie zabiegów opryskiwania w czasie nalotu tego szkodnika na uprawy. Termin nalotu śmietki na plantacje jest ściśle uzależniony od przebiegu pogody, a różnice między kolejnymi latami mogą wynosić nawet kilka tygodni (Szwejda 1975). Dlatego zabiegi ochronne muszą być wykonane w ściśle określonym czasie, w oparciu o prowadzony monitoring nalotu szkodnika na pole. Jedną z dotychczasowych metod jest zbieranie i hodowla poczwarek śmietki otoczonych bobówką w warunkach zbliżonych do naturalnych (Szwejda 1975; Kagan 1976), a następnie notowanie wylotu następnego pokolenia muchówek. Na tej podstawie jest ustalany termin rozpoczęcia zabiegów ochronnych. Innym sposobem jest okresowe odławianie śmietek przy użyciu siatki entomologicznej lub pułapek chwytnych, m.in. żółtych pułapek Moerick'a (Rogowska i Szwejda 2002; Szwejda i Wrzodak 2005). Negatywną stroną stosowania tych metod jest równoczesne odławianie innych gatunków muchówek i owadów, gdzie imagines śmietki kapuścianej to zwykle około 10\% ogółu oznaczonych muchówek w okresie nalotu śmietki na plantację. Poza tym szkodnik ten jest gatunkiem trudnym do identyfikacji i wymaga specjalistycznej znajomości taksonomii owadów. W tych warunkach, takie metody odławiania owadów nie mogą znaleźć szerszego, praktycznego zastosowania. Rozwiązaniem problemu jest zastosowanie użytej w doświadczeniu pułapki zapachowej, zawierającej izotiocyjanian allilu, odławiającej samice śmietki kapuścianej. Pułapka zapachowa umożliwia prowadzenie na bieżąco obserwacji nad nalotem tego szkodnika na plantację oraz na precyzyjne wyznaczenie momentu przekroczenia progu ekonomicznej szkodliwości (Szwejda i Wrzodak 2006). Konieczne jest dalsze prowadzenie doświadczeń pozwalających na opracowanie optymalnych, charakteryzujących się najwyższą skutecznością terminów przeprowadzania zabiegów ochronnych opierających się na monitoringu. Kontynuacji badań wymaga także sprawdzenie wpływu temperatury i wielkości opadów występujących podczas lotu śmietki kapuścianej na dynamikę rozwoju jej populacji i skuteczność przeprowadzanych zabiegów ochronnych.

\section{Wnioski / Conclusions}

1. Zastosowane $\mathrm{w}$ badaniach pułapki zapachowe pozwoliły na określenie początku nalotu oraz momentu przekroczenia progu szkodliwości przez śmietkę kapuścianą.

2. Najwyższą, utrzymującą stały poziom ponad $90 \%$ skuteczność w ochronie kapusty przed śmietką kapuścianą osiągnięto stosując zabiegi ochronne w terminie 5 dni po przekroczeniu progu szkodliwości.

3. Pułapki zapachowe powinny stanowić podstawę do prowadzenia monitoringu nalotu śmietki kapuścianej w ramach systemów ostrzegających o zagrożeniu upraw, stosowanych $\mathrm{w}$ integrowanej ochronie warzyw kapustnych.

Badania realizowano w ramach zadania 1.14 „Prognozowanie zagrożeń powodowanych przez fitofagi występujące na uprawach roślin warzywnych" wchodzącego w skład Programu Wieloletniego pt. „Rozwój zrównoważonych metod produkcji ogrodniczej w celu zapewnienia wysokiej jakości biologicznej i odżywczej produktów ogrodniczych oraz zachowania bioróżnorodności środowiska i ochrony jego zasobów".

\section{Literatura / References}

Bligaard J., Meadow R., Nielsen O., Percy-Smith A. 1999. Evaluation of felt traps to estimate egg numbers of cabbage root fly, Delia radicum, and turnip root fly, Delia floralis in commercial crops. Entomologia Experimentalis et Applicata 90 (2): 141-148.

Bracken G.K. 1988. Seasonal occurrence and infestation potential of cabbage maggot, Delia radicum (L.) (Diptera: Anthomyiidae), attacking rutabaga in Manitoba as determined by captures of females in water traps. The Canadian Entomologist 120 (07): 609-614.

Boczek J., Dąbrowski Z.T. 2005. Zadania systematyki i taksonomii stawonogów a potrzeby nowoczesnej ochrony roślin. [Challenge to arthropod systematics and taxonomy: meeting the leeds of modern plant protection]. Progress in Plant Protection/Postępy w Ochronie Roślin 45 (1): 60-67.

Collier R.H., Finch S., Phelps K. 1991. A simulation model for forecasting the timing of attacks of Delia radicum on cruciferous crops. Bulletin OEPP/EPPO Bulletin 21 (3): 419-424. 
Eckenrode C.J., Arn H. 1972. Trapping cabbage maggots with plant bait and allyl isothiocyanate. Journal of Economic Entomology 65 (5): 1343-1345.

Finch S., Skinner G. 1974. Some factors affecting the efficiency of water traps for capturing cabbage root flies. Annals Applied Biology 77: $213-226$

Finch S., Skinner G. 1982. Trapping cabbage root flies in traps baited with plant extracts and with natural and synthetic isothiocyanates. Entomologia Experimentalis et Applicata 31: 133-139.

Franz J.M., Krieg A. 1975. Biologiczne zwalczanie szkodników. PWRiL, Warszawa, 226 ss.

Kagan F. 1976. Metody prognozowania i sygnalizacji występowania ważniejszych szkodników roślin warzywnych. Część II: Metody sygnalizacji i prognozowania pojawu chorób i szkodników roślin. Instrukcja dla służb ochrony roślin. Inst. Ochr. Roślin, Poznań, $281 \mathrm{ss}$.

Paruch E. 2001. Naturalne i syntetyczne antyfidanty owadów. Wiadomości Chemiczne 55: 93-149.

Ravn H.P., Esbjerg P. 1994. Current Status of monitoring of Delia radicum, Psila rosae and Agrotis segetum in field vegetable crops in Denmark. Bulletin OEPP/EPPO Bulletin 17: 51-54.

Rogowska M., Szwejda J. 2002. Porównanie dwóch typów pułapek do odławiania imagines śmietki kapuścianej (Delia radicum L.). [Comparison of two trap types to catch of cabbage root fly adults (Delia radicum L.)]. Progress in Plant Protection/Postępy w Ochronie Roślin 42 (2): 622-624.

Rogowska M. 2005. Stosowanie nowej pułapki feromonowej do monitorowania nalotu piętnówki kapustnicy (Mamestra brassicae L.) występującej na warzywach kapustowatych. s. 51-53. Ogólnopolska Konferencja Upowszechnieniowa „Nauka - Praktyce”. Skierniewice, 20.10.2005, 76 ss.

Ruszkowski J. 1933. Wyniki badań nad szkodliwą fauną Polski na podstawie materiałów z lat 1919-1930. Roczniki Nauk Rolniczych $3(3): 1-24$.

Ruszkowski J., Prüffer J., Krasucki A., Minkiewicz S., Keler S., Strawiński K., Pronin J. 1935. Wyniki badań nad szkodliwą fauną Polski. Roczniki Nauk Rolniczych, Cz. B: Szkodniki Roślin 2 (2-3): 2-20.

Szwejda J. 1975. Ekologia śmietki kapuścianej (Hylemyia brassicae (Bché)) (Diptera: Anthomyiidae). Roczniki Nauk Rolniczych, Seria E - Ochrona Roślin 5 (1): 43-74.

Szwejda J. 1999. Stan i potrzeby badań entomologicznych w zakresie ochrony roślin warzywnych przed szkodnikami. [Status of entomology researches in protection of vegetable crops in Poland]. Progress in Plant Protection/Postępy w Ochronie Roślin 39 (1): $43-51$.

Szwejda J. 2004. Przegląd szkodników i ich wrogów naturalnych aktualnie występujących na warzywach kapustowatych w Polsce. Nowości Warzywnicze 39: 97-104.

Szwejda J. 2010. Fitofagiczna entomofauna warzyw kapustowatych występująca na plantacjach w Polsce w latach 1861-2010. s. 16-19. Ogólnopolska Naukowa Konferencja Warzywnicza „Postęp w integrowanej produkcji warzyw kapustowatych”. Skierniewice, 21.10.2010, 60 ss.

Szwejda J., Wrzodak R. 2005. Ogólnopolski system monitorowania śmietki kapuścianej na plantacjach kalafiora, brokułu i kapusty pekińskiej w uprawie jesiennej. s. 45-53. Ogólnopolska Konferencja Upowszechnieniowa „Nauka - Praktyce”. Skierniewice, 20.10.2005, 76 ss.

Szwejda J., Wrzodak R. 2006. Ogólnopolski system monitorowania śmietki kapuścianej na plantacjach warzyw kapustowatych. [Nationwide system for monitoring of cabbage root fly (Delia radicum) on cabbage plantations in Poland]. Progress in Plant Protection/Postępy w Ochronie Roślin 46 (1): 270-275.

Talhouk A.M.S. 2002. Insects \& Mites: Injurious to Crops in Middle Eastern Countries. American University of Beirut Press, Beirut, $176 \mathrm{pp}$.

Traynier R.M.M. 1965. Chemostimulation of oviposition by the cabbage root fly, Erioischia brassicae (Bouche). Nature (London) 207: 218-219.

Wiech K., Kałmuk J., Pawelec A. 2001. Wykorzystanie pułapek feromonowych do prognozowania niektórych szkodników warzyw. [Use of pheromone traps for forecasting some of the pests of vegetables]. Progress in Plant Protection/Postępy w Ochronie Roślin 41 (2): 450-453. 